\title{
Tarbiyah Ukhwah Islamiyah Dalam Tradisi Kearifan Lokal Marsialap Ari
}

\author{
Rossa Hadana Harahap*, Musaddad Harahap, Lina Mayasari Siregar \\ Institut Agama Islam Negeri Padangsidimpuan, Indonesia*, Universitas Islam Riau, \\ Indonesia, Sekolah Tinggi Agama Islam Barumun Raya, Indonesia \\ *Jl. T. Rizal Nurdin No. Km 4, RW.5, Sihitang, Padangsidimpuan Tenggara, Kota Padang \\ Sidempuan, Sumatera Utara 22733 \\ *Email: rossahadanaharahap@gmail.com
}

\begin{abstract}
In recent years, Indonesia has been busy with discussions of intolerance, antidiversity and anti-NKRI. This phenomenon is actually very contrary to the culture of Indonesian society in general. This paper wants to see how the nature of the marginalized local wisdom of the Tapanuli, Mandailing, Angkola and surrounding communities is in instilling ukhwah. With the literature study approach, it is found that the local wisdom tradition contains very noble tarbiyah values to realize ukhwah in social life. The partial tradition is carried out in three aspects of community life, namely; in the fields of cleaning (agriculture, rice fields, gardens, and others), Siriaon events (parties and thanksgiving), and Siluluton (sad news). In principle, the tradition of marsialap ari is a symbol of strength to maintain the existence of society so that they can live harmoniously and make it easier for one another. In the context of the 21st century, this partial marsialap ari tradition needs to be preserved and still be passed on to the younger generation so that a sense of brotherhood, togetherness and tolerance between people is maintained.
\end{abstract}

Keywords: Tarbiyah, Ukhwah Islamiyah, Local Wisdom, Marsialap Ari

\begin{abstract}
Abstrak: Indonesia beberapa tahun belakangan ini disibukkan oleh diskusi intoleransi, anti kebhinekaan, dan anti NKRI. Fenomena ini sebetulnya sangat bertentangan dengan kultur masyarakat Indonesia pada umumnya. Tulisan ini ingin melihat bagaimana hakikat kearifan lokal marsialapan ari masyarakat Tapanuli, Mandailing, Angkola dan sekitarnya dalam menanamkan ukhwah. Dengan pendekatan studi pustaka, maka ditemukan bahwa tradisi kearifan lokal marsialap ari mengandung nilai-nilai tarbiyah yang sangat luhur untuk mewujudkan ukhwah dalam kehidupan sosial. Tradisi marsialap ari dilakukan dalam tiga aspek kehidupan masyarakat, yaitu; dalam bidang Paiaskon (pertanian, sawah, kebun, dan lainnya), acara Siriaon (pesta maupun syukuran), dan Siluluton (kabar duka). Prinsipnya tradisi marsialap ari merupakan simbol kekuatan untuk menjaga eksistensi masyarakat agar tetap bisa hidup rukun dan memudahkan satu sama lain. Dalam konteks abad 21 ini tradisi marsialap ari perlu untuk dilestarikan dan tetap diwariskan kepada generasi muda agar rasa persaudaraan, kebersamaan, dan toleransi antar sesama tetap terjaga.
\end{abstract}

Kata Kunci: Tarbiyah, Ukhwah Islamiyah, Kearifan Lokal, Marsialap Ari

Jurnal Pendidikan Agama Islam Al-Thariqah Vol. 5, No. 2, Juli - Desember 2020

Received: 05 December 2020; Accepted 10 December 2020; Published 13 December 2020

*Corresponding Author: rossahadanaharahap@gmail.com 


\section{PENDAHULUAN}

Indonesia merupakan negara urutan keempat dengan populasi terbanyak diseluruh dunia. Penduduknya sangat plural yang terdiri dari suku, ras, tradisi, adat istiadat, bahasa, dan agama. Berkaitan dengan keyakinan, Indonesia dihuni oleh penduduk yang mayoritas muslim yang terbentang dari sabang sampai merauke. Bila dilihat dari akar sejarah Indonesia sulit untuk dinafikan bahwa Islam adalah kekuatan yang memiliki ajaran untuk mencintai tanah air dan sekaligus mengakomodir segala bentuk perbedaan.

Namun saat ini Islam dihadapkan pada problem gerakan islamophobia yaitu prasangka terhadap orang muslim atau orang yang dipersepsikan muslim. Perasangka ini didasarkan pada klaim bahwa Islam adalah agama inferior yang mengancam nilai-nilai tatanan kehidupan bermasyarakat, berbangsa, dan bertanah air (Moordiningsih, 2014: 73-84). Padahal bila ditelaah lebih dalam Islam sesungguhnya memiliki ajaran yang luhur dan sangat menjunjung tinggi nilai-nilai persatuan, artinya Islam bukanlah agama inferior seperti yang dituduhkan oleh oknum-oknum tertentu. Sikap inferior hakikatnya bukanlah persoalan teologis apalagi persoalan kedangkalan ajaran Islam, tetapi masalah ini sangat erat kaitannya dengan kesenjangan sosial, ekonomi, dan bahkan politik. Ketidak seimbangan memperlakukan ketiga bidang itu akan berdampak kepada hilangnya kepercayaan, pada saat yang bersamaan akan timbul sikap saling curiga mencurigai (Umar, 2010: 169186). Maka boleh dikatakan "kesenjangan adalah kerawanan yang besar". Substansi dari kesenjangan adalah ketidakmerataan akses (Syawie, 2011: 213-219).

Kesenjangan kehidupan di abad 21 ini sulit untuk dielakkan. Arus globalisasi akan selalu memaksa orang untuk memilih hidup individualis. Fenomena seperti ini terjadi hampir disemua Negara di dunia termasuk di Indonesia, tak terkecuali di daerah Mandailing, Tapanuli Selatan, Angkola, dan sekitarnya. Adapun kemorosotan rasa sosial masyarakat sesungguhnya tidak bisa dipisahkan dari semangat pemekaran dan arus urbanisasi yang terjadi di daerah tersebut. Hal ini sesuai apa yang disebut dalam Tri Ratnawati bahwa ada lima hal yang sering terjadi akibat pemekaran, yaitu konflik dan kekerasan, menurunnya jumlah penduduk dan PAD secara drastis, menyempitnya luas wilayah dan beban daerah induk, perebutan wilayah dan masalah ibu kota pemekaran, dan perebutan asset daerah dari daerah induk (Ratnawati, 2010: 122-235). Jadi penyebab mundurnya rasa ukhwah masyarakat tentu tidak bisa dilepaskan dari masuknya arus dan agenda-agenda modernisasi ke daerah-daerah baru ini.

Dalam Setiawan disebutkan ada dua faktor yang menyebabkan terjadinya masalah sosial, yaitu ada yang relatif tetap dan ada yang sifatnya berkembang. Faktor yang relatif tetap misalnya letak geografis dan daya dukung alam. Sementara faktor yang berkembang adalah berupa keadaan sosial, keadaan budaya yang menyangkut pengetahuan dan keterampilan, adat-istiadat, situasi politik dan kebijaksanaan penguasa (Hamzah, 2007: 215). Oleh karena itu ukhwah adalah sebuah keniscayaan untuk dapat memutus matai rantai faktor-faktor yang mengakibatkan lahirnya problemproblem sosial yang berkepanjangan. Hal ini sangat memungkinkan dilakukan oleh umat Islam karena bersaudara merupakan asas ajaran dalam agama, sebagaimana dipraktikkan oleh Nabi Muhammad SAW dan para sahabatnya (Fata dan Najib, 2014: 319-334).

Terlepas dari banyaknya faktor yang mengakibatkan lunturnya pola hidup bersama, tentu setiap elemen bangsa wajib untuk melakukan kajian agar problem-problem tersebut dapat diminimalisir. Dengan demikian tujuan 
kajian ini adalah sebuah refleksi terhadap kegelisahan itu. Oleh karena itu dianggap penting untuk melakukan kajian tentang tradisi kearifan lokal marsialap ari dalam membina Ukhwah Islamiyah.

\section{KONSEP TEORI}

Ukhwah Islmiyah berasal dari bahasa Arab, terdiri dua kata tetapi memiliki satu pengertian. Kata pertama adalah ukhwah dan kata kedua adalah Islmiyah. Dalam kamus bahasa Arab ukhwah adalah bentuk jama' dari kata akha yang bermakna menjadi saudara, kawan atau teman akrab. Karena kata ukhwah merupakan bentuk jama' maka makna ukhwah adalah persaudaraan (Munawwir, 1997: 12). Kata ukhwah pada mulanya bermakna memperhatikan. Makna asal ini merupakan adanya sebuah kelaziman bahwa persaudaraan lahir karena adanya rasa dan perhatian yang sama di dalam persaudaraan itu sendiri. Jadi istilah ukhwah mengalami perkembangan sehingga pada kahirnya ukhwah dimaknai dengan kebersamaan antar sesama, baik karena saudara kandung, saudara seibu, saudara se ayah, atau saudara sesusuan. Sementara secara majaz ukhwah meliptui persamaan suku, agama, profesi, perasaan, dan sebagainya (Shihab, 1996: 478). Dalam bahasa Indonesia pemakaian kata ukhwah sudah menjadi lumrah ditengah-tengah masyarakat. Sehingga dalam KBBI disebutkan bahwa ukhwah sama dengan persaudaraan (KBBI, 2008: 1581). Hanya saja dalam KKBI tidak disebut lebih jauh model persaudaraan yang dimaksud. Istilah persaudaraan hanya digunakan secara umum saja.

Sedangkan kata yang kedua adalah Islamiyah. Kata islamiyah merupakan kata sifat terkait dengan Islam. Istilah Islam sendiri merupakan kata yang berasal dari bahasa Arab yaitu aslama - yuslimu yang berarti berserah diri, patuh, taat, dan tunduk. Selain itu kata Islam juga disebut berasal dari beberapa akar kata seperti asslim yaitu perdamaian, kerukunan, dan keamanan. Assalam bermakna selamat, sejahtera, dan bahagia. Salimun yaitu suci dan bersih (Wahyudin, 2009: 16).

Dari makna kedua istilah di atas, maka dapat dipahami bahwa Ukhwah Islamiyah merupakan persaudaraan yang dilandasi oleh adanya perhatian dan kebersamaan yang dilandasi oleh ajaran Islam itu sendiri. Artinya bahwa ukhwah islamiyah seperti disebut oleh Shihab (1996: 478-479) sangat erat kaitannya dengan bagaimana Islam mengajarkan kepada umatnya untuk membangun persaudaraan yang baik antar sesama, terutama persaudaraan sesama Islam. Meskipun begitu Ukhwah Islamiyah juga harus dibangun dengan pihak lain baik karena adanya hubungan garis keturunan maupun karena hanya adanya persamaan dalam aspek lain. Selama persaudaraan itu dilandasi oleh ajaran Islam, maka persaudaraan itu tetap bernilai positif.

Dalam ajaran Islam sendiri, sesuai petunjuk nash-nash yang ada, maka ukhwah isalmiyah ini terdiri dari Ukhwah Ubudiyah yaitu persaudaraan karena sama-sama makhluk dan memiliki prinsip yang sama yaitu tunduk kepada Allah SWT. Ukhwah Insaniyah atau Basyariah yaitu persaudaraan karena memiliki hakikat yang sama yaitu manusia yang berasal dari asal yang sama. Ukhwah Wathaniyah yaitu persaudaraan karena sebangsa dan setanah air. Dan Ukhwah fi din al-Islam yaitu persaudaraan antar sesama muslim (Shihab: 1996: 479).

Dari pandangan di atas, maka Ukhwah Islamiyah pada dasarnya mencakup seluruh aspek kehidupan, terutama kehidupan sosial. Dengan pemahaman seperti ini maka misi Islam sebagai agama rahmat li al-'alamin jauh lebih implikatif bila dibandingkan dengan pemabatasan pemahaman bahwa ukhwah islamiyah hanya berkaitan dengan persaudaraan sesama Islam. Menjaga dan memperkuat ukhwah sesama Islam 
memang tidak keliru, bahkan Islam sendiri mengajarkan bahwa orang-orang beriman itu adalah bersaudara dan mereka harus mendamaikan saudaranya jika terjadi perselisihan. Hal inilah yang disebut oleh Allah SWT. dalam Q.S. AlHujurat ayat 10 :

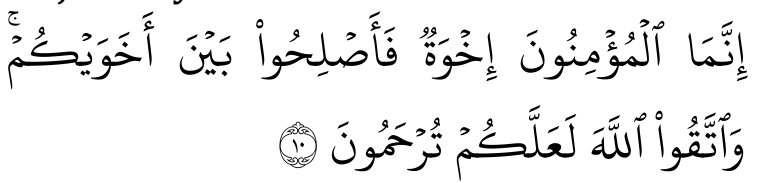

Meskipun begitu, karena petunjuk nash juga tidak hanya membatasi persaudaraan hanya sesama Islam, maka upaya membangun hubungan yang baik dengan pihak lain harus tetap menjadi perhatian. Intinya adalah upaya menjalin hubungan dengan pihak lain tersebut harus tetap berada pada wilayah ajaran Islam itu sendiri.

Menurut Suriati, et al., (2019: 941946) bahwa Ukhwah Islamiyah ini penting, tetapi dalam prakteknya umat Islam harus lebih variatif dalam menginternalisasikannya. Untuk dapat menginternalisasikannya boleh dengan pendekatan taaruf, tafahum, ta'awun, maupun tafakul. Pendekatan-pendekatan seperti ini merupakan kunci keberhasilan untuk mewujudkan Ukhwah Islamiyah yang baik.

Adapun korelasi teori tentang Ukhwah Islamiyah ini dengan tema penelitian adalah bahwa kearifan lokal merupakan warisan para leluhur yang lahir dari tradisi-tradisi kehidupan bermasyarakat di sama lampau. Tidak dapat dipungkiri bahwa kearifan lokal terkadang memiliki ajaran yang sangat luhur dan tidak bertentangan dengan ajaran Islam. Oleh karena itu tema penelitian ini secara umum sangat syarat dengan nilai-nilai Ukhwah Islamiyah. Seperti diketahui tema penelitian ini adalah tradisi kearifan lokal marsialap ari. Tradisi ini merupakan ajaran leluhur masyarakat di daerah Mandailing, Tapanuli Selatan, Angkola, Padanglawas Utara, Padanglawas, dan sekitarnya.
Untuk itu dalam penelitian ini, akan dilakukan upaya rekonstruksi tentang bagaimana fenomena marsialapan ari dalam perpektif pendidikan Islam dalam mewujudkan ukhwah islamiyah.

\section{METODE PENELITIAN}

Pendekatan yang digunakan dalam penelitian ini adalah studi kepustakaan yaitu sebuah pendekatan yang dimaksudkan untuk dapat menghimpun data-data penelitian dari berbagai sumber yang relevan dengan tema penelitian. Sumber data penelitian ini adalah buku, artikel, surat kabar, dan lainnya selama ada kaitannya dengan penelitian. Teknik pengumpulan data dilakukan dengan editing, organizing, dan finding. Kemudian instrument penelitian ini adalah peneliti sendiri (human instrument).

Sementara untuk menganalisis data yang sudah dikumpulkan dilakukan dengan dua cara yaitu analisis data deduktif dan analisis data interpretatif. Analisis data deduktif dimaksudkan untuk menarik sebuah kesimpulan yang lebih konkrit dari fakta-fakta yang dikategorikan besifat umum. Sementara analsisis data interpretatif dimaksudkan untuk dapat menghasilkan makna yang lebih normatif dari data-data yang sudah melalui proses editing, organizing, dan finding. Jadi penelitian ini dimaksudkan untuk dapat menghasilkan kesimpulan yang menggambarkan bagaimana tarbiyah ukhwah islamiyah dalam kearifan lokal tradisi marsialapan ari.

\section{HASIL DAN PEMBAHASAN}

Setelah dilakukan analisis terhadap berbagai sumber dalam penelitian ini, maka dapat dikemukan tiga poin penting terkait dengan tarbiyah ukhwah islamiyah dalam tradisi kearifan lokal marsialap ari di daerah Tapunuli, Mandailing, Angkola, Padanglawas Utara, Padanglawas, dan sekitarnya, yaitu; Konsep Tradisi Marsialap Ari (Tolong Menolong), 
Marsialap Ari (Tolong Menolong) Perspektif Islam, dan Pentingnya Melestarikan Marsialap Ari (Tolong Menolong).

\section{Konsep Tradisi Marsialap Ari (Tolong Menolong)}

Istilah "marsialap ari" secara terminologi terdiri dari dua suku kata yaitu "alap" (jemput) dan "ari" (hari), kemudian kata "alap" dimasuki awalan "mar" sehingga menjadi "marsialap" (saling menjemput). Jadi, kedua suku kata ini (marsialap ari) ketika digabungkan akan menghasilan satu pengertian baru yaitu saling menyisihkan waktu dan kesempatan untuk dapat membantu meringankan beban orang lain. Sementara secara etimologi marsialap ari dapat dipahami sebagai kegiatan tolong menolong yang dilakukan oleh masyarakat batak di daerah Mandailing, Tapanuli Selatan, Angkola maupun sekitarnya (Pulungan, 2018: 348-354). Seiring perubahan waktu maka istilah marsialap ari berubah dialek, yang oleh masyarakat terkadang disebut menjadi marsalapan ari.

Konsep marsialap ari ini merupakan warisan leluhur masyarakat Mandailing, Angkola, Tapanuli Selatan dan sekitarnya. Konsep ini memiliki filosofi tersendiri, seperti disebutkan oleh Zulkarnain bahwa marsialap ari merupakan ajaran tolong menolong yang saling menguntungkan. Praktek tradisi ini dilakukan secara bersama-sama, baik orang tua maupun yang muda-mudi (naposo-nauli bulung), bahkan anak-anak pun ikut serta terlibat di dalamnya walaupun peran mereka hanya sekedar meramaikan saja (Pulungan, 2018: 348354).

Adapun wilayah pekerjaan yang paling populer untuk digotong royongkan (marsialap ari) adalah masalah pertanian/sawah, mulai dari mencangkul (manajak), menanam padi (manyuan eme), membersihkan sawah (marbabo), panen (manyabi), sampai membawa hasil panen dari sawah ke rumah (manaru eme). Hal ini sesuai dengan apa yang disebut oleh Muhammad Takari bahwa salah satu kultur masyarakat tradisional Batak Mandailing-Angkola dan sekitarnya adalah sistem sosioekonomi yang berdasar kepada pertanian. Mereka melaksanakan pekerjaan berat menjadi ringan, terutama dalam taraf huta (kampung) dengan cara bergotong royong (marsialap ari) (Takari, 2007: 8).

Selain masalah yang berkaitan pertanian/sawah atau kebun, marsialap ari juga dilakukan dalam hal suasana duka (Siluluton) dan masalah suasana suka (Siriaon). Misalkan masalah duka, masyarakat Batak Mandailing/Angkola dan sekitarnya sangat dipantangkan tidak ikut serta dalam prosesi fardu kifayah jenazah. Ketika ada orang meninggal dunia masyarakat kampung (huta) akan menghentikan semua aktivitasnya mulai dari pagi sampai ba'da sholat zuhur (pemakaman jenazah). Bagi sebagian masyarakat yang bekerja sebagai PNS atau di kantor juga akan menyempatkan diri untuk melayat, baru kemudian mereka berangkat kerja. Sementara untuk menyampaikan kabar duka kepada sanak saudara di luar kampung (huta), anakanak muda dengan suka rela akan berangkat naik sepeda atau motor untuk menyampaikan (paboahon) kabar duka dengan membawa list nama yang sudah ditulis oleh keluarga dekat yang meninggal dan dibantu oleh hatobangon (orang yang dituakan).

Kemudian pada sore hari atau malam harinya secara bergantian masyarakat akan ikut hadir kirim doa di rumah duka. Biasanya anak-anak gadis (nauli bulung) datang ke rumah duka pada sore hari baca surah yasin, selepas mereka baru kaum ibu-ibu (ina-ina). Pada malam harinya antara magrib dan isya kaum bapak dan anak-anak muda ikut serta membaca surah al-ikhlas di masjid, dan disebagian tempat dilakukan sore 
hari menjelang magrib di depan rumah duka. Baru selepas sholat isya kaum bapak dan anak-anak muda akan mengikuti baca surah yasin di rumah duka. Kemudian pada pagi harinya baca surah yasin pun dilakukan dipemakaman. Biasanya hal ini dilakukan tiga hari secara berturut-turut. Selain masalah kirim do'a dalam pelaksanaan tolong menolong (marsialap ari) bagi keluarga duka, masyarakat pun akan mengumpulkan beras atau uang untuk membantu beban keluarga yang berduka. Bantuan materil ini juga ada yang bersifat terorganisir melalui perangkat desa dan juga dilakukan atas kesepakatan beberapa kelompok masyarakat desa yang disebut julo-julo (arisan). Hanya saja istilah julojulo ini lebih akrab dikenal dalam kegiatan-kegaiatan di luar kabar duka (siluluton).

Jadi implementasi marsialap ari dalam kondisi duka memiliki dua fungsi. Pertama, membantu secara moril yaitu memberikan sokongan secara bathin kepada keluarga yang ditinggalkan agar mereka tetap tabah atas musibah yang datang kepada mereka. Sebab musibah itu dalam ajaran Islam pada hakikatnya datang dari Allah SWT. karena manusia adalah ciptaan Allah SWT, maka tentu mereka juga harus kembali kepada Allah SWT (Q.S. Al-Baqarah ayat 156). Jadi, Hal ini sebenarnya sangat sejalan dengan konsep pendidikan Islam yang menganjurkan agar seseorang betul-betul memiliki rasa kepedulian, empati, saling menjaga, melindungi, menghormati, dan sebagainya. Rasa kemanusiaan semacam ini pada akhirnya akan dapat membentuk toleransi dan solidaritas sosial yang tinggi (Saihu, 2020: 127-148). Kedua, membantu secara materil. Dalam pendidikan Islam membantu orang yang kena musibah juga merupakan persoalan penting yang harus ditunaikan oleh setiap orang. Kewajiban orang yang tidak kena musibah kepada orang yang kena musibah adalah berempati dan memberikan bantuan meteril untuk meringatkan beban mereka dan juga untuk menghilangkan kesedihan yang tertimpa musibah (Awaliah, 2019: 87).

Sedangkan masalah suka cita (Siriaon) masyarakat di Mandailing, Tapanuli Selatan, Angkola, Padanglawas, Padanglawas Utara maupun sekitarnya memiliki konsep tolong menolong (marsialap ari) yang variatif. Misalkan dalam hal pesta ada yang diistilah marjulo-julo (arisan). Boleh jadi marjulomarjulo itu dalam hal beras, kayu bakar, daging, kentang, bahan-bahan untuk membangun rumah, peralatan-peralatan rumah tangga, dan sebagainya. Namun yang paling terpenting konsep marsialap ari dalam hal suka cita (siriaon) adalah keikut sertaan seluruh warga masyarakat dalam meringankan beban yang punya hajat, mulai dari membersihkan beras, menyiapkan bumbu, memotong-motong daging, memasak nasi dan gulai, sampai menghidangkannya kepada tamu yang berdatangan. Kesemua itu akan dilakukan dengan suka rela tanpa mengharapkan imbalan dari yang punya hajat. Momen yang serupa juga nantinya akan dilakukan bagi siapa saja yang punya hajat. Jadi, prinsip dan semangat tolong menolong seperti ini sangat sejalan dengan apa yang diajarkan dalam Q.S. Al-Maidah ayat 2. Pripsinya tolong menolong yang dilakukan oleh masyarakat dalam hal siriaon syarat dengan nilai-nilai kebaikan yang tidak bertentang dengan ajaran Islam. Dengan demikian tolong menolong (marsialap ari) adalah sesuatu yang sangat penting untuk terus direalisasikan karena tradisi ini pada dasarnya sangat relevan untuk membentuk ukhwah antar sesame masyarakat. Dengan terbinanya rasa ukhwah tersebut, maka sikap fanatisme, eksklusifisme, radikalisme, dan konflik antar masyarakat akan dapat dihindari.

Namun, bila diamati dengan seksama dewasa ini sangat tampak adanya penurunan semangat marsialap 
ari dan ilai-nilai marsialap ari pun sudah mulai terdegradasi akibat kemajuan zaman. Fenomena pola hidup masyarakat saat ini sudah mulai mengarah kepada paradigma hidup individualis, bahkan paradigma uang/upah dalam kegiatan paiaskon, siluluton, dan siriaon sudah mulai terbentuk dibenak masyarakat. Padahal pesan moral dari marsialap ari di tengah-tengah kehidupan masyarakat dewasa ini sangat penting.

Budaya marsialap ari perlu dilestarikan sebagai bagian dari kearifan lokal. Fakta sejarah telah menunjukkan bahwa marsialap ari sangat membantu menata kehidupan masyarakat yang tertib dan damai. Hal ini seperti diungkapkan oleh Zulkarnain bahwa marsialap ari akan dapat membentuk karakter yang memiliki suasa kekeluargaan, kolaborasi, dan semangat kerja. Dengan konsep marsialap ari akan mampu membentuk enam karakter yaitu semangat kerjasama, saling membantu, saling toleransi, nilai kejujuran, nilai kepedulian atau ikhlas, dan ketaatan beribadah (Pulungan, 2018: 348-354).

\section{Marsialap Ari (Tolong Menolong) Perspektif Islam}

Dalam Islam tolong menolong (marsialap ari) disebut ta'awun memiliki makna yang komprehensif dan sistemik. Karena sebagian ulama menafsirkannya sebagai prinsip besar dalam kehidupan secara menyuluruh. Hadits Nabi Muhammad saw menganalogikan ta'awun sebagai suatu bangunan yang saling menguatkan satu sama lain atau suatu badan. Apabila ada yang sakit, rasa sakit tersebut akan terasa oleh bagian yang lainnya (Abdussalam, 2004: 25-40).

Dengan prinsip tolong-menolong (marsialap ari) kehidupan manusia akan lebih mudah dan sejahtera, karena tidak seorang pun tahu nasibnya di masa akan datang, sebab pengetahuan manusia sangat terbatas, biasanya manusia hanya bisa merencanakan, sedangkan apa yang akan terjadi besok pagi atau di masa yang akan datang ia tidak tahu. Sebagai manusia, dia hanya diberi kemampuan untuk mengatur hidup dan kehidupannya agar mencapai kebahagiaan baik di dunia maupun di akhirat dengan cara memrpoteksi hal-hal yang bernilai negatif, baik dalam bentuk musibah, kecelakaan, kebakaran atau kematian, dapat diminimalisasi kerugiannya (Abdussalam, 2004: 247-248).

Sementara Maikomah menyebutkan tolong-menolong adalah bagian dari akhlak (etika). Etika Tolong menolong merupakan sikap yang senang menolong orang lain, baik dalam bentuk material atapun tenaga dan moral. Seseorang hidup di dalam lingkungan masyarakat wajib tolong-menolong apabila seseorang mempunyai hubungan kemanusiaan (Maikomah, 2018: 204-212). Jadi tradisi marsialap ari (tolong menolong) bukanlah sesuatu yang munkar, sebab apa yang dipraktekkan dalam konsep marsialap ari sama sekali tidak bertentangan dengan aqidah Islam. Seandainya pun ada yang menyalahi, maka idealnya yang diperbaiki itu adalah praktiknya, bukan konsep masrialap arinya. Konsep marsialap ari tetap memiliki urgensi sebagai bagian dari kearifan lokal yang dapat merajut dan memerkuat ukhwah sesama muslim, bahkan juga dengan kelompok yang berbeda keyakinan. Selama tidak terkait dengan aqidah, maka bekerjasama untuk kemaslahan umum tetaplah diperkenan. Hal ini sebenarnya sangat sejalan dengan konsep moderasi beragama yang dikembangkan oleh Kementerian Agama RI. Dalam kehidupan yang sangat heterogen seperti Indonesia kebaikan moral bersama sangat relevan dikembangkan, baik secara individual, kelompok, maupun kelembagaan (Hakim, 2019: 11).

Bukti lain bahwa marsialap ari adalah tradisi baik dapat dilihat dalam konteks Asuransi kolektif (ta`awun) yang 
merupakan aktivitas yang dihalalkan. Menurut Hasanah, asuransi jenis ini merupakan implementasi sikap tolongmenolong dalam kebajikan dan ketakwaan yang diperintahkan Allah (Hasanah, 2013: 240-268). Allah berfirman surah Al-Ma'idah ayat 2 "...Dan tolong-menolonglah dalam mengerjakan kebajikan dan takwa, dan jangan tolongmenolong dalam berbuat dosa dan pelanggaran. Dan bertakwalah kepada Allah, sesungguhnya Allah amat berat siksa-Nya".

Adapun dalil tentang tolong menolong (marsialap ari) jelas ada dalam Al-Qur'an. Dalil ini dimaksudkan bukan untuk pembenaran, tetapi dalil ini hanya untuk memastikan apakah konsep marsialap ari bertentangan dengan prinsip-prinsip ajaran Islam. Dalam AlQur'an disebutkan bahwa untuk memungkinkan adanya kerjasama (marsialap ari), Allah SWT. telah menganugerahkan kelebihan-kelebihan di antara umat manusia sebagian atas sebagian yang lain. Mengenai masalah ini, Allah SWT. berfirman dalam Surah AlZukhruf ayat 32 "Kami telah meninggikan sebagian mereka atas sebagian yang lain beberapa derajat, agar sebagian mereka dapat mempergunakan sebagian yang lain. Dan rahmat Tuhanmu lebih baik dari apa yang mereka kumpulkan".

Kelebihan yang dianugerahkan Allah SWT. dalam ayat di atas tidak selalu berarti bahwa seseorang dianugerahi derajat yang lebih tinggi dari yang lain, tetapi hal ini dimaksudkan bahwa setiap orang pasti memiliki kelebihan dan kekurangan. Dengan kelebihan yang ada pada seseorang, dia bisa menutupi kekurangan yang ada pada orang lain, dan sebaliknya (Hasanah, 2013: 241).

Dengan perbedaan suku, ras, dan agama akan muncul kemampuan yang saling melengkapi, saling tolong menolong dan saling mengasihi satu sama lainnya, hal ini ditegaskan dalam AlQur'an surah Al-Anbiyaa' ayat 107 'Dan tiadalah Kami mengutus kamu, melainkan untuk (menjadi) rahmat bagi semesta alam".

Di samping ayat Al-Qur'an, Rasulullah SAW. juga mengingatkan perlunya tolong-menolong dalam kebaikan dan ketakwaan "Seorang Muslim adalah saudara orang Muslim lainnya. Ia tidak boleh menzhaliminya dan tidak boleh membiarkannya diganggu orang lain (bahkan ia wajib menolong dan membelanya). Barangsiapa membantu kebutuhan saudaranya, maka Allâh Azza wa Jalla senantiasa akan menolongnya. Barangsiapa melapangkan kesulitan orang Muslim, maka Allah akan melapangkan baginya dari salah satu kesempitan di hari Kiamat dan barangsiapa menutupi (aib) orang Muslim, maka Allâh menutupi (aib)nya pada hari Kiamat".

\section{Pentingnya Melestarikan Marsialap Ari (Tolong Menolong)}

Indonesia memiliki kearifan lokal yang sangat banyak jumlahnya. Kearifan lokal ini akan dapat abadi jika diamalkan dalam kehidupan yang konkrit sehingga tetap mampu untuk merespon perkembangan zaman yang semakin kompleks. Upaya implementasi kearifan lokal akan berhasil jika nilai-nilai kearifan lokal mampu menjelma dalam kebijakankebijakan negara. Idealnya Negara harus menggali kearifan lokal tersebut, sehingga setiap kebijakannya seiring sejalan dengan tradisi kearifan lokal yang ada ditengah-tengah kehidupan masyarakat (Fajarini, 2014: 123-140). Salah satu kearifan lokal itu adalah marsiap ari. Kearifan lokal ini sangat syarat dengan nilai-nilai yang perlu diperhatikan dalam setiap mengambil kebijakan.

Tolong menolong (marsialap ari) merupakan sebuah tradisi luhur yang dapat membina hubungan baik dengan semua orang, baik sesama keluarga, tetangga, teman, antar rekan kerja. Hakikat dari marsialap ari adalah 
menolong diri sendiri, dan hal ini jugalah yang diyakini dalam ajaran agama, jadi menolong orang (marsialap ari) tidak ada batasannya.

Dengan menolong orang lain hidup akan terasa bermakna dan berarti, jauh dari kegelisahan. Banyak orang sekarang merasa hampa dan gelisah, karena sudah dikuasai oleh pradigma kehidupan individualistis yang notabenenya sangat bertentangan dengan prinsip ajaran agama.

Untuk mengembalikan dedikasi masyarakat terhadap kepekaan sosial, maka salah satu caranya adalah menggalakkan kembali tradisi-tradisi baik warisan nenek moyang dahulu. Setiap daerah tentu memiliki falsafah tolong menolong, terkadang bisa jadi tradisi itu sudah dianggap tidak relevan, padahal di sana banyak hikmah yang bisa diangkat kembali dalam diskursusdiskursus akademik untuk menyelesaikan persoalan sosial yang semakin kompleks. Salah satu tradisi itu ada di masyarakat Batak Mandailing, Angkola dan sekitarnya yaitu "marsialap ari". Dewasa ini dalam prakteknya marsialap ari hanya dilakukan oleh sesama keluarga dekat dan itupun tampaknya hanya bergulir dikalangan kaum ibu-ibu. Jadi agar tradisi baik ini tidak hilang, maka perlu kiranya pemerintah mencari terobosan baru untuk menghidupkan kembali tradisi marsialap ari. Tradisi marsialap ari ini harus diwariskan turun temurun kepada generasi muda supaya kepekaan sosial mereka tumbuh lebih baik.

\section{PENUTUP}

Dalam tataran praktik marsialap ari terbagi kepada tiga hal yaitu urusan pertanian, sawah, kebun (paiaskon), acara pesta (siriaon), dan suasana duka (siluluton). Dalam masyarakat Batak Mandailing, Angkola dan sekitarnya sendiri ketiga hal ini masih tetap dipraktekkan oleh masyarakat walaupun terkadang terkesan hanya sesama keluarga dekat saja. Sementara bagi kalangan anak muda istilah ini sudah tidak akrab lagi, sebab secara komunal marsialap ari bukan lagi bahasa popular ditengah-tengah kehidupan masyarakat. Tetapi bagi kalangan orangtua, terutama kalangan kaum ibu marsialap ari masih akrab dan mereka masing sering marsialap ari untuk menyelesaikan berbagai perkejaan.

Selain itu konsep marsialap ari perlu untuk dilestarikan, karena secara teoritis konsep ini tidak bertentangan dengan ajaran tauhid, malah bila dilihat indikator-indikator praktik marsialap ari, tampaknya sangat sejalan dengan ajaran pendidikan Islam itu sendiri. Jadi untuk membina ukhwah dan persatuan masyarakat baik seagama maupun lintas agama sangat tepat salah satunya dengan meningkatkan intensitas penerapan marsialap ari. Oleh karena itu, pemerintah hendaknya melakukan kajian serius agar tradisi marsialap ari ini tetap bisa terealisasi dalam kehidupan masyarakat.[]

\section{DAFTAR RUJUKAN}

Abdussalam, Aam. "Teori Sosiologi Islam (Kajian Sosiologi Terhadap Konsepkonsep Sosiologi dalam Al-Quran AlKarim)" Jurnal Pendidikan Agama Islam Ta'lim, 12.1 (2004): 25-40.

Awaliah, Lia, and Muhammad Alif. "Musibah dalam Perspektif Hadis." Holistic al-Hadis 5.2 (2019): 68-91.

Eerriyanto. Analisis Isi: Pengantar Metodologi Untuk Penelitian Ilmu Komunikasi dan Ilmu-Ilmu Sosial Lainnya. Jakarta: Pranadamedia Group, 2015.

Fajarini, Ulfah. "Peranan kearifan lokal dalam pendidikan karakter." SosioDidaktika: Social Science Education Journal 1.2 (2014): 123-130.

Fata, Ahmad Khoirul, and M. Ainun Najib. "Kontekstualisasi Pemikiran KH. Hasyim Asy'ari tentang Persatuan 
Umat Islam." Miqot: Jurnal Ilmu-ilmu Keislaman 38.2 (2014): 319-334.

Hasanah, Uswatun. "Asuransi dalam Perspektif Hukum Islam AsySyir'ah" Jurnal Ilmu Syari'ah dan Hukum 47. 1 (2013): 240-268.

Maikomah, Selfi, Erlina Zahar, and Harbeng Masni. "Analisis Nilai Etika Tolong-Menolong Tokoh Hepi Dalam Novel Anak Rantau Karya A. Fuadi." Jurnal Ilmiah Dikdaya 8.1 (2018): 204-212.

Moordiningsih, "Islamophobia dan Strategi Mengatasinya." Buletin Psikologi 12.02 (2014): 73-84.

Munawir, AW. Kamus Al-Munawir. Surabaya: Pustaka Progresif, 1997.

Nasional. Departemen Pendidikan. Kamus Besar Bahasa Indonesia, Jakarta: Pusat Bahasa, 2008.

Nur, Makmur Jaya. "Da'wah in Form of Ukhuwah Islamiyah." 1st Borobudur International Symposium on Humanities, Economics and Sosial Sciences (BIS-HESS 2019). Atlantis Press, 2020.

Pulungan, Dedi Zulkarnain. "Budaya 'Marsialap Ari'refleksi Pembentukan Karakter Masyarakat Mandailing. "Seminar Nasional Pendidikan Bahasa Indonesia 1.1 (2018): 348354.

Ratnawati, Tri. "Satu dasa warsa pemekaran daerah era Reformasi: kegagalan otonomi daerah." Jurnal Ilmu Politik, Edisi 2.1 (2010): 122235.

Saifuddin, Lukman Hakim. Moderasi Beragama. Jakarta: Badang Litbang dan Diklat Kementerian Agama RI, 2019.

Saihu, Saihu. "Pendidikan sosial yang terkandung dalam Surat At-Taubah Ayat 71-72." Edukasi Islami: Jurnal Pendidikan Islam 9.01 (2020): 127 148.

Setiyawati, dan Hamzah, "Analisis Pengaruh PAD, DAU, DAK, dan Belanja Pembangunan Terhadap
Pertumbuhan

Ekonomi,

Kemiskinan, dan Pengangguran". Jurnal Akuntansi dan Keuangan Indonesia 4.2 (2007): 215.

Shihab, M. Quraish. Wawasan Al-qur'an Tafsir Maudhu'i Atas Pelbagai Persoalan Umat. Bandung: Mizan, 1996.

Syawie, Mochamad. "Kemiskinan dan Kesenjangan Sosial." Jurnal Informasi, 16.03 (2011): 213-219.

Takari, Muhammad. Kebudayaan Dalam Konteks Suksesi Kepemimpinan di Sumatera Utara, Makalah pada Seminar Dua Negara Hubungan Melayu Serantau: Sumatera Malaysia, yang diselenggarakan tanggal 24 sampai 26 Agustus 2007 di Melaka. Melaka: USU, 2007.

Umar, Ahmad Rizky Mardhatillah. "Melacak Akar Radikalisme Islam di Indonesia." Jurnal Ilmu Sosial dan Ilmu Politik 14.2 (2010): 169-186.

Wahyudin. et al. Pendidikan Agama Islam untuk Perguruan Tinggi. Jakarta: Grasindo, 2009. 